\title{
EMOCIONES Y DEMOCRACIA: ACERCA DE LA COMPASIÓN Y LA IRA EN NUSSBAUM Y GIANNINI
}

\author{
María José López Merino ${ }^{1}$ \\ Universidad de Chile \\ mjlopezmerino@gmail.com
}

"Cómo encontrar una forma de asociación que defienda y proteja, con la fuerza común, la persona y los bienes de cada asociado, y por la cual cada uno, uniéndose a todos los demás, no obedezca más que a sí mismo y permanezca, por lo tanto, tan libre como antes"(J.J. Rousseau). "La democracia no es una alternativa a otros principios de vida en sociedad. Es la idea de la vida misma en comunidad, un nombre para una vida en comunión libre y enriquecedora"

(John Dewey).

\section{RESUMEN / ABSTRACT}

En la deliberación pública de una democracia, ¿qué lugar tienen las emociones, especialmente las emociones de la compasión y la ira?; es la pregunta general que guía esta investigación. Para dar respuesta a ella nos centraremos en el pensamiento de dos pensadores que aunque pertenecen a espacios culturales y académicos diferentes guardan algunos puntos de contacto en sus perspectivas filosóficas: Marta Nussbaum y Humberto Giannini. Haciéndonos cargo del affective turn (Ahmed 2014) nos interesa indagar que impacto tienen las pasiones de la compasión y de la ira sobre una democracia incompleta, o débil. Esto es especialmente relevante en momentos de transformación y perfeccionamiento democrático, cuando una comunidad camina hacia una democracia más participativa e inclusiva. Así, en un primer momento, siguiendo las pistas que nos entregan estos dos filósofos, nos dedicaremos a describir formas de compasión y formas de ira que benefician la deliberación democrática y aquellas que la obstaculizan.

Palabras ClaVE: democracia, crisis democrática, emociones, ira,compasión- NussbaumGiannini

\section{EMOCIONES Y DEMOCRACIA: ACERCA DE LA COMPASIÓN Y LA IRA EN NUSSBAUM Y GIANNINI}

In the public deliberation of a democracy, what's place have emotions? Especially the emotions of compassion and rage? Is the general question that guides this research. To respond to it, we will focus on the thought of two thinkers who, although they belong to different cultural and academic spaces, have some points of contact in their philosophical perspectives: Martha Nussbaum and Humberto Giannini.

Dra. en Filosofía del derecho moral y política, profesora Asociada Departamento de Filosofía, Facultad de Filosofía y Humanidades, Universidad de Chile, miembro del Grupo de Estudios Humberto Giannini. 
Taking charge of the affective turn (Ahmed, 2014) we are looking for investigate the impact on an incomplete democracy they have the passions of compassions and rage have. Especially in the path of democratic transformation, towards more participatory and inclusive ways. Thus, at first, we will dedicate ourselves to describing forms of compassion and forms of rage that benefit democratic deliberation and those that hinder it.

KEYWORDS: Democracy, Democratic crisis, emotions, rage, compassion, Nussbaum-Giannini.

\section{La democracia en problemas: los problemas de la democracia}

RA La idea de democracia hoy en día es inseparable de la historia de su crisis y las críticas que ha venido recibiendo desde hace mucho tiempo. La clásica visión de la democracia liberal representativa, bajo un modelo elitista, pluralista de equilibrio de distintas fuerzas y poderes sociales (Macpherson 95), comienza a ser pensada desde una perspectiva crítica justamente como una democracia débil e insuficiente (Barber 2003).

En este contexto, surgen los intentos, desde hace décadas, de ampliar el paradigma democrático, no para superarlo sino para realizarlo en plenitud. En este sentido, el giro deliberativo en las teorías de la democracia (deliberative turn) es una respuesta al déficit de la democracia representativa (Habermas 1998, Gutmann y Thompson 1996). Junto a estos avances, las discusiones acerca de la democracia fuerte (Barber 2004) ${ }^{2}$, democracia radical (Mouffe y Laclau 1985) o más específicamente post-representativa (Keane 2009) van en esta línea. Aunque se trata de posiciones que guardan muchas diferencias y discusiones en los puntos relevantes de sus respectivas posiciones, las une la necesidad de reformular la democracia: dando un nuevo protagonismo a los ciudadanos, al discurso público y la deliberación amplia e inclusiva como formas específicas de encarnar una política democrática real y significativa para sus ciudadanos. A esta tarea amplia y trabajosa se suman además nuevos componentes que que se proponen realizar la idea de la igualdad de derechos para todos. Componentes sociales, culturales, ambientales, de género, van encaminados a considerar no solo una democracia política, sino también una democracia social y cultural, (Benhabib 1996, Fraser 2000, Kilmlicka 1995), incluso económica ${ }^{3}$ (Roemer 1986, Van Parijis 1996).

2 La idea de una democracia fuerte "descansa en la idea de una comunidad autogobernada de ciudadanos, unidos más por la educación cívica que por intereses homogéneos. Ciudadanos ilustrados para la actividad mutua y las empresas comunitarias en virtud de sus actitudes cívicas e instituciones participativas, en lugar de por su altruismo y su natural bondad. Así también, una democracia fuerte que-desafía la política de élites y masas que escenifican la democracia en occidente y al hacerlo- ofrece una alternativa importante a la que hemos denominado democracia blanda: es decir, la democracia instrumental, representativa e institucional" (Barber 2004, 187).

"None of the problems that have defined capitalism for several hundred years have been solved; that is to say, poverty and unemployment, heteronormative violence between genders and sexual orientations, racism and the colonial domination of many global regions by 
A este panorama debemos agregar que después del ciclo de movimientos y manifestaciones democráticas de 2011 en todo el mundo, estas reflexiones se profundizan, sobre todo ante la reaparición de la democracia como la práctica real y genuina de quienes quieren participar aquí y ahora, exigiendo sus derechos (Demirovic 2017, 299). Más allá de las condiciones y demandas locales, lo que se puede distinguir con claridad en estos movimientos es el alegato a favor de la democracia: la necesidad de democratizar la democracia (Demirovic 2017, 304). La separación entre las elites y la ciudadanía, la creciente despolitización junto al crecimiento de la ignorancia y el desinterés en las cuestiones políticas, como también, la creciente influencia del dinero en la política, podrían ser algunas de las principales causas de estos nuevos reclamos de los ciudadanos a la democracia (Hansen y Rostbell 2015, 502).

A nivel regional, se suman las considerables dificultades que presentan las democracias en América Latina. Democracias que han sido descritas como incompletas, poco profundas en sus instituciones y prácticas (Smith y Ziegler 2008). Esto considerando que mayoritariamente cuentan con elecciones periódicas y libres, pero se aprecia en ellas restricciones sistemáticas a los derechos ciudadanos, haciendo posible identificar elementos autoritarios y no democráticos que afectan la calidad y capacidad del sistema. Especialmente en los países latinoamericanos que durante las décadas de los $80 \mathrm{y}$ 90 transitaron desde regímenes autoritarios a regímenes democráticos (Elster 2003), heredando instituciones y obstáculos ineludibles. Sociedades en las que la construcción cultural de una democracia plural, activa y participativa es todavía una tarea, un desafío por realizar (O’Donnell 2017, 80).

\section{Nussbaum y Giannini: Emociones, democracia y conflicto}

En este contexto de crisis y reforma de las actuales democracias, es que queremos indagar en un campo de problemas: el campo de las pasiones políticas desde la perspectiva de autores contemporáneos relevantes y pertinentes como son: Marta Nussbaum ${ }^{4}$, Humberto Giannini ${ }^{5}$. Pese a sus diferencias, estos autores tienen en común el interés

privileged centres, the exploitation of human labour capacity and the massive increase of social wealth concentrated in the hands of a small rich minority, all alongside the destruction of nature (not just climate change, but soil erosion, desertification, and shortage of clean drinking water too) as a prerequisite for human life" (Demirovic 298, 2018).

4 Nusssbaum, pensadora norteamericana, defensora de una democracia liberal, rawlsiana, pensadora del mundo clásico, profesora de autores griegos y romanos, especialmente de Aristóteles, en la Universidad de Chicago, entre otras. Desde hace algunos años viene trabajando en la experiencia de las emociones en la vida cotidiana y especialmente en la vida política cotidiana. Autora de varios libros sobre el tema: Paisajes de pensamiento (2001), El ocultamiento de lo humano: repugnancia, vergüenza y ley (2004) Emociones políticas (2013), La ira y el perdón (2014), La monarquía del miedo (2018), entre otros.

5 Giannini es un pensador y académico chileno, profesor de Filosofía Medieval durante años en la Universidad de Chile, formado en el pensamiento clásico y con ciertas simpatías, pero 
y el trabajo acerca de las pasiones ${ }^{6}$ o emociones, desde el campo de la experiencia cotidiana, dialogando desde allí con diversas tradiciones contemporáneas ${ }^{7}$. Al mismo tiempo, comparten algunas fuentes filosóficas relevantes: Aristóteles y las tradiciones aristotélicas. Si bien Giannini se centra más en la lectura de Santo Tomás, Nussbaum además de la influencia aristotélica, suma la importante herencia de la tradición y lectura estoica acerca de las pasiones.

Preocuparnos de las emociones políticas que están en juego en una democracia incompleta y que busca perfeccionarse, no solo supone aceptar que las democracias deliberativas no involucran a, menos no únicamente, concesos. Hay conflictos irreductibles (Mouffe), que expresan los sistemas democráticos muchas veces mediante pasiones públicas. Hay incluso una pluralidad irreductible de opiniones y discursos ciudadanos, que en sí misma no es un obstáculo para la democracia, sino su condición de posibilidad, sobre todo si la pensamos como una "democracia fuerte".

No se trata simplemente de estudiar el rol que las emociones como elementos no cognitivos, irracionales que obstruyen el desarrollo de una democracia deliberativa racional (McLeverty 2014, 34). Instrumentos de dominio y servidumbre voluntaria, como han sido intensamente estudiados en los regímenes totalitarios, autocráticos o simplemente populistas.

Nos interesa más bien, haciéndonos cargos del affective turn (Ahmed 2014) indagar, al menos en parte, en el impacto que tienen sobre una democracia incompleta nuestras pasiones, especialmente en este camino de transformación democrática, hacia orientaciones más participativas e inclusivas en la deliberación pública. En este ámbito es posible distinguir las emociones que benefician la deliberación democrática y aquellas que la obstaculizan. En lo que sigue analizaremos únicamente las formas de la compasión y de la ira, en su aporte a estas tareas, alimentando o dificultando el quehacer central de la deliberación democrática.

también ciertas críticas hacia el pensamiento fenomenológico contemporáneo, uno de sus temas centrales es la experiencia cotidiana. Autor de una obra bastante original y de libros como: Desde las palabras (1981), La reflexión cotidiana (1987), Del bien que se espera y del bien que se debe (1997a) La metafísica eres tú (2007).

6 Entendemos por pasiones el amplio territorio de nuestra vida afectiva, que involucra la ética, la estética y la vida animal -al menos desde Aristóteles - como luego las filosofías del helenismo (epicureísmo, estoicismo), las filosofías empiristas modernas, el romanticismo europeo y más contemporáneamente por las orientaciones tanto fenomenológicas como pragmáticas y de ciencias cognitivas-, se describen como un vasto campo de fenómenos, distinguibles pero relacionados.

7 Nussbaum con la tradición del empirismo, el liberalismo político y las ciencias cognitivas. Giannini con las tradiciones fenomenológicas europeas y el pensamiento hispanoamericano. 


\section{Acerca de las pasiones políticas}

Desde una perspectiva contemporánea, 'Pasiones' o emociones son en primer lugar, algo que nos sucede a nosotros, es decir, que experimentamos en primera persona (Solomon 1993, 67), experiencias o estados mentales que nos afectan involucrando distintos grados de intensidad y permanencia en el tiempo. Desde la perspectiva que estamos asumiendo, se relacionan en segundo lugar, con aspectos fisiológicos y sociológicos, concretos, aunque no se identifican con ellos.

Para Nussbaum y tomando pie no sólo Ética a Nicómaco, sino también, La poética y sobre todo La retórica: “(D)esde el punto de vista de Aristóteles, las emociones no son fuerzas animales ciegas, sino partes inteligentes y discriminadoras de la personalidad, estrechamente relacionadas con creencias de cierta clase, y por tanto sensibles a modificaciones cognitivas" (Nussbaum 1996: 303).

En este sentido, para la autora norteamericana las emociones tienen un carácter bifronte: por un lado, son formas concretas de conocer los objetos y el mundo a partir de nuestras creencias e impresiones acerca de ellos -tienen una estructura intencional dirá la fenomenología-. Por otro lado, nos hablan de quién es y qué valora el sujeto sintiente. Nussbaum llama al primer elemento el 'contenido cognitivo' de las emociones siguiendo a Solomon $(1993,2007)$ y es un punto de especial controversia de la autora con las posiciones empiristas y las ciencias cognitivas que trabajan emociones. Mientras que al segundo elemento lo llama la estructura eudaimónica de las emociones (Nussbaum 2014: 15), es decir, la tendencia de las emociones de señalarnos, implícita o explícitamente, una determinada concepción de vida buena del sujeto sintiente.

En una democracia, según Nussbaum, debe existir una activa preocupación por las emociones que pueden darle estabilidad a la cultura democrática y permitir o promover el diálogo y deliberación democrática aun en épocas de crisis y tensión (Nussbaum 2014, 15). Desde la perspectiva de una democracia liberal, que la autora defiende, no puede asumirse una posición "neutra" a la hora de promover por ejemplo la compasión, base de cualquier forma de solidaridad cívica, e inhibir la indiferencia o el desprecio, base de la la segregación social. Desde esta perspectiva una educación emocional resulta básica para el desarrollo de una cultura democrática. Una educación de este tipo, nos permitiría ampliar la mirada, más allá del individuo o el grupo social y sus intereses específicos, permitiendo el desarrollo de un interés por el bien común (Nussbaum 2014, 16). Y al mismo tiempo, permitiría protegernos frente a tendencias egoístas y narcisistas que suelen tener consecuencias destructivas y antidemocráticas (Nussbaum 2014, 16). Al mismo tiempo, la promoción activa de emociones que apoyen la democracia no debe en ningún sentido inhibir la crítica y la discusión. Muy por el contrario, sin una crítica racional y amplia que muestre una opinión pública diversa y compleja, es imposible pensar en una democracia deliberativa ${ }^{8}$.

8 "Tanto los principios en sí como las emociones que estos suscitan deben estar continuamente sometidos a escrutinio y crítica, y las voces discrepantes o disconformes desempeñan una 
Por su parte, Giannini, en su tratamiento de la experiencia cotidiana, del lenguaje y de la experiencia moral, rescata también, la vida de las pasiones, como una parte esencial de nuestra experiencia reflexiva acerca de nosotros mismos (Giannini 1997a: 21), ante los otros (Giannini 1997a: 25 y ss.) y en definitiva, al mundo, como mundo común (Giannini 1988: 26). La experiencia común, que está en el centro de su reflexión cotidiana, es también un sentir común.

Aunque no tematiza de manera separa el tema de las emociones, salvo en el rescate de la experiencia del defecto moral que suponen los pecados capitales (Giannini 1997, 149 y ss.) En su descripción de la experiencia moral, las ideas de vínculo moral y su quiebre son también experiencias emocionales, especialmente en torno al tema de la ofensa moral (Giannini 1997a).

Al mismo tiempo, su consideración de la democracia, que es considerada básicamente como la búsqueda de la experiencia común, aparece también profundamente ligada al diálogo y al conflicto ${ }^{9}$. Coincide en este punto con Nussbaum y considera central para la democracia las experiencias del diálogo y la deliberación. Para el filósofo chileno "en democracia la instauración de una 'sociedad dialogante' es un imperativo moral” (Giannini 1987, p. 83). En este sentido, la democracia puede ser descrita como la experiencia generalizada de un diálogo ciudadano, y que ocurre en todos sus niveles y de manera privilegiada en la calle, el espacio ciudadano y político por experiencia ${ }^{10}$.

En este sentido, la democracia consiste en un diálogo interminable sobre la base de las diferencias y el conflicto ${ }^{11}$. Afirma Giannini, "la experiencia común es experiencia de un conflicto siempre renovado; un anhelo de aclaración jamás satisfecho plenamente" (Giannini 1987a, p. 264). Este conflicto es una condición de posibilidad de esa misma democracia y no constituye un escollo o problema que superar. En este carácter constitutivo, positivo y hasta cierto punto insuperable del conflicto Giannini coincide con Nussbaum, quien llama a esta conflictividad las colisiones trágicas en la esfera política (Nussbaum 2014, 327), propias de una democracia que aspira a tratar con el conflicto y sus emociones sin destruirse.

función muy valiosa a la hora de mantener la concepción general resultante dentro de unos cauces verdaderamente liberales y sometidos al control de la ciudadanía (Nussbaum 2014, 20).

9 "Lo que verdaderamente importa es que este diálogo (ético-político) de segundo nivel, surja de la experiencia común (y de sus conflictos), y vuelva a ella. ¿No es esto lo que llamamos "democracia"? (Giannini 1995: 405).

10 En el campo ciudadano más cotidiano ocurre la conversación callejera que para el autor es transgresión que interrumpe la rutina de circulación en la calle, y que hace posible la restauración de la experiencia común (Giannini 1987, 47).

11 "La vida democrática, además de normas que se aceptan, es necesariamente conflicto, conflicto que se resuelve siempre, pero a medias, porque surge otro conflicto surge otro aspecto de las transacciones" (Giannini 2015, 68). 


\section{La compasión: la experiencia fundante de la democracia}

La compasión, advierte Nussbaum siguiendo a Aristóteles, es el dolor por el infortunio o sufrimiento ajeno (Nussbaum 2008, 345) Para sentir compasión por otro(s) debemos considerar 1) la gravedad de los sucedido, es decir, no se trata de un hecho trivial-juicio de magnitud-, 2) la no responsabilidad del agente, que se trata de un daño que no merece -juicio de inmerecimiento-y, 3) que aquello sucedido es algo que nos podría haber sucedido a nosotros -juicio de similitud de posibilidades-, (Nussbaum 2008, 345 y ss.). Este último punto es más bien complejizado y relativizado por la autora, ya que con facilidad puede derivar en una simpatía excluyente, que considera sujetos de compasión solo a aquellos que son como yo o pertenecen al mismo grupo que yo

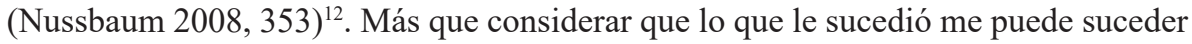
a mí, ya que somos "de los mismos", de lo que se trata es de incorporar al otro en el propio proyecto eudaimonista: que el otro no sufra injustamente, incluso otro distinto en el que no me reconozco, puede ser parte importante de mi propio idea de desarrollo y felicidad (juicio eudaimonista) y para el desarrollo de la comunidad política como tal ${ }^{13}$. Esta capacidad de padecer-con para Nussbaum, como ya para Rousseau, debería ser parte de la educación sentimental, encaminada a convertir a los niños y jóvenes en verdaderos ciudadanos ${ }^{14} \mathrm{y}$ resulta clave en una democracia donde la diversidad de proyectos de vida, creencias, incluso culturas, está en la base. Esto significa asumir la tarea de enseñar el buen juicio cívico, como las habilidades psicológicas que permitan la compasión: que Nussbaum entiende básicamente como el desarrollo de la empatía y la capacidad de desarrollar la imaginación acerca de las experiencias de otros (Nussbaum 2014, 372).

En este punto, para entender los límites de la "compasión” o cuando esta de pasar a ser una emoción que promueve los vínculos de una comunidad que es diversa y democrática, a ser una emoción destructiva y con potencialidades antidemocráticas,

12 Este juicio relativo a las posibilidades parecidas requiere una demarcación: ¿qué criaturas estoy dispuesto a considerar que comparten posibilidades conmigo y cuáles no? (Nussbaum 2008, 355).

13 Del mismo modo, para que se despierte la compasión se debe considerar el sufrimiento de otra persona como una parte significativa del propio esquema de objetivos y metas. Se deben tomar las penurias de otra persona como algo que afecta al propio florecimiento. En efecto, quien se compadece se hace vulnerable en la persona de! otro. Es este juicio eudaimonista, y no el juicio de las posibilidades parecidas, lo que parece ser un componente necesario de la compasión. (Nussbaum 2008, 358).

14 "Rousseau argumenta que su familiaridad con las vicisitudes usuales de la fortuna impedirá a Emilio (que no habita en una sociedad enferma) excluir a los pobres o a los miembros de las clases bajas, puesto que sabrá que las personas pierden sus haberes y su estatus a cada momento, así como sus derechos políticos. Pero también nos dice que en su propia sociedad muchas personas deslindan su pensamiento de las posibilidades que tienen las personas de las clases bajas: por eso los nobles y los reyes no se compadecen de aquellos que están por debajo de ellos" (Nussbaum 2008, 356). 
nos puede ayudar el contrapunto que puede poner Arendt con su crítica a la compasión. Recordemos la conocida crítica que en On Revolution (1990), la filósofa hará acerca de la compasión como motor de cierto momento decisivo de la Revolución francesa. Enfrentándose directamente a Rousseau, nos dirá que la compasión una vez generalizada, se transforma en piedad y puede desatar la irrupción de la completa irracionalidad política, el comienzo de procesos imparables de violencia que hacen aparecer las peores crueldades (Arendt 1990, 79). La piedad desde esta perspectiva tiende a destruir las diferencias de la esfera pública igualitaria y conflictiva, homogeniza esa esfera, pierde las posibilidades de mostrar diferencias y abrir un espacio a la discusión (Arendt 1990, 63). Dejando únicamente el espacio mudo de la violencia (Arendt 1993, 226). Será importante no perder de vista esta crítica a la compasión como emoción política y analizar cuidadosamente sus peligros, ligados como plantea Arendt, al nexo entre compasión y violencia, como también, la piedad como herramienta colectiva de masificación, un instrumento para las ideologías.

En Giannini no hay un desarrollo específico de la compasión, pero en su filosofía práctica de la experiencia moral y la experiencia cotidiana hay dos descripciones del vínculo con el otro, que estarían en la base de nuestra "experiencia común" que se relacionan con la compasión tal como la describe Nussbaum. En primer lugar, el autor chileno nos habla de com-patencia con el otro (Giannini 1978b, 29). La com-patencia sería la experiencia originaria mediante la cual, comparecemos con los otros ante una realidad común ${ }^{15}$. La realidad de ese espacio común es la realidad de un punto de convergencia, ante el objeto, ante el mundo. Somos igualmente testigos, espectadores del fenómeno de mundo. A partir de esta com-patencia, como base puede existir un intento de recuperación de una convivencia verdaderamente democrática (1995, 1997b, 2015).

En una línea convergente con la idea de la comp-patencia, Giannini habla directamente de la hospitalidad -siguiendo a Levinas-como la actitud intencional fundante de la experiencia común, que caracteriza al ser humano entregado al acontecimiento del mundo, el alma callejera que en uno de sus artículos identifica con Odiseo (1987b, 11). Un alma callejera es la que acoge la realidad de lo extraño, sale a su encuentro, abraza esa novedad del acontecimiento, contempla el espectáculo de todo lo que es, recuperando el asombro del mundo. Se trata de una disposición, abierta hacia el otro y el mundo, que acoge el don de ese regalo que es la realidad misma. En este caso la donación siempre ocurre con los otros (1987a y 1987b). Hay un texto específico en el que el filósofo muestra que esta actitud hospitalaria tiene un importante fundamento para la convivencia: Según su etimología la palabra, hospitalidad vendría del latín arcaico 'hostis', que significa según Giannini tanto 'huésped' como 'enemigo'. Ahora bien, siguiendo a Benveniste, Giannini aclara que habría un estrato más profundo de significación que de hecho haría posible esta ambigüedad: 'hostio' sería básicamente

15 "Queremos expresar con este término el objetivo aparecer ante todos de una realidad. Se trata, pues, de una realidad que comparece ante una multiplicidad de conciencias, como en el espectáculo. El filósofo ha de hablar de la compatencia de lo que es, tal como comparece allí donde aparece" Giannini 1978b, 29, nota 11. 
igualdad, 'hostire': igualar derechos. Igualdad y reciprocidad de derechos que es el fundamento de la antigua institución de la hospitalidad (Giannini 1997b, 340). No es el único momento y lugar en el que Giannini refiere a esta igualdad originaria, fundamento de cualquier forma de hospitalidad como vínculo, y de toda forma de com-patencia como fundamento. Existiría en realidad, una experiencia de horizontalidad radical, que por cierto podría ser la base de la com-patencia y también de la hospitalidad como disposición afectiva de acogida. En otro texto, llama a esta experiencia: "igualdad animal" ${ }^{16}$ y al menos sugiere que su extensión sobrepasa la especie humana. Se trata de la experiencia del reconocimiento de una igualdad primera de los seres sintentes. Hay aquí una nueva conexión posible con Nussbaum, para quienes la compasión es también una emoción que se extiende más allá de la especie humana (Nussbaum 2008, 113).

\section{Las formas de la ira}

\subsection{La ira ante la injusticia}

La emoción de la ira en su sentido clásico, que Nussbaum toma de Aristóteles, consiste en la afección o pasión $(\pi \mathrm{a} \theta \mathrm{o} \varsigma)$ "de un cierto pesar o dolor causado por un desprecio, merma o daño sufrido, que despierta un apetito de venganza futura" (Aristóteles, Rhet, II 1378a 31-33 y Nussbaum 2018a: 37). En este sentido se trata de una emoción reactiva, que se encuentra atada tanto al pasado, por el daño infringido como al futuro, pues está empeñada en una liberación de ese dolor, ligada a alguna forma de restauración (Nussbaum 2018a, 36).

En este esquema, la ira nos habla de un mundo injusto, donde existe, sin embargo, la posibilidad de reparación.

Como reconstruye la autora norteamericana, a partir de Aristóteles de nuevo, la visión tradicional de la ira, desde la perspectiva de quien la sufre puede resumirse en:

1. La experiencia de un desprecio o ultraje (oligōría), injusticia.

2. De uno mismo o de personas cercanas a uno

3. Llevado a cabo de modo injusto o inapropiado (mē prosēkóntōn)

16 "Sentirse como esa humanidad patente que es el prójimo, en la apertura niveladora que la calle confiere al transeúnte, no es un descubrimiento reflexivo, ni poético o sentimental. Es previo a todo eso. Corresponde a un reconocimiento animal, instintivo que una sociedad jerarquizada ha venido sepultando. Y al punto inaudito de convertir la realidad del otro en un problema teórico. En las profundidades del mar, los pequeños peces miran a los ojos del buzo, seguros de encontrar el punto de acceso a la profundidad esencial del visitante. Pero el individuo humano, en la soledad de sus raciocinios se ha planteado en serio la posibilidad de ser él la única conciencia. Él, la única mirada. Solus ipse" (Giannini 1984, $52)$. 


\section{Acompañado de dolor}

5. Que despierta un deseo de retribución en quien la sufre (Nussbaum 2018a, 40)

Por su parte, Giannini reconoce como ya hemos dicho que el conflicto moral se despliega a partir de la experiencia del daño; en su primera etapa este daño se manifiesta como Ofensa (Giannini 1997a, 48), Se trata justamente de la experiencia de un sujeto que sufre un daño infringido inmerecidamente. La ofensa es no solo la experiencia negativa inicial del proceso, sino que una experiencia afectiva, se sufre (Bruna 2021). A la ofensa como momento inicial de conflicto moral le siguen el enjuiciamiento y la justificación, como momentos que, mediante el lenguaje, intentan reponer la simetría, el equilibrio, frente a la injusticia sufrida (Giannini 1997a: 80).

Este modelo Ofensa-Enjuiciamiento-Justificación (Giannini 1997a: 51 y ss.), puede ser vinculado con facilidad con la descripción que el mismo Giannini hace un poco más adelante, en el mismo libro, cuando describe el pecado de la ira. Siguiendo en esto directamente a Santo Tomás ${ }^{17}$, el pensador chileno nos advierte: "El iracundo es tal, porque cree percibir en los hechos del presente, la consecución de un mal anterior, justamente de una ofensa (violencia a su honra, a sus principios, a sus ideales,) una injusticia sufrida, que hay que suprimir. La iracundia es la expresión de un resentimiento. Pero también, una forma de liberarse de él" (Giannini 1997a: 174).

Lo que apreciamos en la descripción de Giannini es el mismo esquema aristotélico ya presentado por Nussbaum como el esquema clásico para entender la ira y que se reduce a la respuesta emocional esperable, a la hora de sufrir una injusticia. Desde esta perspectiva, no se trata de la ira como una irrupción irracional. Más bien, se trata de una ira que involucra una lectura de la realidad, en la que es capaz de reconocer que "el bien que se espera" (en lenguaje de Giannini) por parte de cada integrante de la comunidad, no se cumple. Se trata así de una ira moralmente útil, en la medida en que permite identificar una injusticia y expresa a la vez, un impulso de reparación, busca reponer el bien que se debe al sujeto injustamente dañado (Giannini 1997a: 174).

Desde la perspectiva de una democracia, esta ira funcionaría entonces al menos como índice moral, alarma que llama la atención ante la opinión pública ciudadana, haciendo visibles las injusticias: sin este 'color' que aporta la ira al clima emocional, probablemente esa ofensa sería ilegible en el gris de la vida cotidiana, tanto para el ofensor como para el ofendido, como también, sería ilegible la necesidad de reparación.

Por otro lado, basándonos en Giannini más que en Nussbaum en esto, esta ira ante la injusticia, puede acompañar y movilizar las fuerzas personales y sociales, que hacen posible el enjuiciamiento. La ira motiva, consciente o inconscientemente

17 Giannini cita aquí las Quaestiones Disputae De Malo de Tomás de Aquino, quien distingue entre una ira per zelum (legítima) y una ira per vitium (ilegítima) (cf. De malo, q. 14 art. 2). Obviamente, Tomás de Aquino se basa en Aristóteles (Eth. VII) para establecer esta distinción. 
nos moviliza en el proceso para buscar en el futuro una reparación, una esperanza de liberación ${ }^{18}$. En esto la ira ya lo decíamos, mueve, para Giannini.

Sin embargo, Nussbaum se desmarca prontamente de esta lectura clásica, dejando ver los peligros que esta búsqueda unilateral de justicia siguiendo a la ira, puede dejar en su camino de restauración, en el contexto de una democracia.

Ya en Aristóteles esta búsqueda de justicia implicaría la búsqueda de venganza, y esta venganza engendra otro nuevo mal, en una cadena. La ira ante la injusticia puede rápida e imperceptiblemente transitar hacia una ira vengativa y traer formas de violencia desatada muy peligrosas para una democracia (Nussbaum 2018a: 43 y ss).

Giannini también reconoce esta posibilidad de torcer el sentido de búsqueda de justicia y liberación propia de la ira ante la injusticia. Siguiendo a Santo Tomás, la ira se convierte en un vicio -y en un pecado capital- cuando lo que se pretende ya no es recuperar o reparar el daño recibido sino infringir un nuevo daño (Giannini 1997a:173). En este sentido, Giannini nos advierte "(s)i la intención se fija principalmente en el mal de quien nos vengamos, y en esto encuentra su satisfacción y goce, entonces la ira es absolutamente ilícita (...) Así la iracundia es un vicio, cuando el precio de liberación de un resentimiento e injusticia, es la destrucción del prójimo" (Giannini 1997a: 176).

En un sentido parecido, pero más radical, Nussbaum considera que si bien el elemento vengativo es parte de la ira, hay un tipo específico de ira que no tiene este elemento y puede ser útil a la democracia: la llama ira de transición (Nussbaum 2018a: 50 y ss). Se trata de aquella ira que se despega de la búsqueda de venganza y justicia particular, y se transforma en la búsqueda del bien futuro para la comunidad (Nussbaum, 2018a: 52). Encontramos aquí una especie de ira límite, ya que no incluye el deseo de venganza, porque se ha desprendido de él $(2016,404)$. Una "ira neutra", despersonalizada que se centra en la comunidad y su restauración de la justicia y la igualdad, más que en la reparación del individuo.

El movimiento conceptual de ambos autores es hasta cierto punto contrario pero coincidente en la posibilidad de separar ira ante la injusticia e ira vengativa.

Tomando dos metáforas patológicas podríamos proponer que la ira ante la injusticia es una emoción moralmente funcional a la democracia en tanto podría funcionar a) como un reactivo, que en un examen hace visible la presencia de un patógeno, las injusticias u ofensas poco visibles (función expresiva); b) o como un fármaco (función emancipatoria) que impulsa a la acción, al manifestarse en la esfera pública comienza a atacar las bases de la injusticia esa ira legítima en el espacio público democrático. Igual no hay que perder de vista que en exceso un fármaco puede convertirse en veneno.

18 "Yo creo que la ofensa se siente, aunque no siempre se hace conciencia de ella (...). La ofensa está debajo, entonces; como no se manifiesta, no se manifiesta sino en cosas que son a veces condenables, como la violencia" (Giannini 2015: 120). Giannini sostiene que "la ira y todo el descontento que no se sabe por qué, se da, a veces, de modo descontrolado" (2015: 120). 


\subsection{La ira vengativa en contra de la democracia}

Como ya decíamos, Nussbaum reconoce la posibilidad de una ira de transición, pero al mismo tiempo advierte, 2018a y 2019) el gran peligro que la ira vengativa puede tener para una sociedad democrática. Vinculada al miedo, al resentimiento, a la vulnerabilidad y a la impotencia de las sociedades en crisis (Nussbaum 2019: 82) ${ }^{19}$, la ira vengativa nos puede impulsar a cometer graves errores de juicio acerca de la realidad (Nussbaum 2019: 29) y graves daños cuando llega a las principales instituciones de la democracia.

¿Cómo opera esta ira vengativa? El movimiento de la venganza imagina que el daño al victimario algo mitiga el dolor o resarce el daño de la víctima (2016: 47). El cuestionamiento de Nussbaum es directamente al funcionamiento moral de este mecanismo, ella se pregunta "¿Por qué alguien que ha sido herido gravemente vería con esperanza el momento de hacerle algo desagradable al infractor? (2016: 47).

En este punto, la autora revela una cuestión moralmente crucial: no es posible encontrar un nexo causal entre el malestar infringido a otros y la recuperación o restauración propia frente al mal recibido; esta idea, si es verdad que gobierna el quehacer de la ira vengativa es una idea falsa. Expresivamente, Nussbaum se pregunta:”¿Por qué alguien inteligente pensaría que infligir dolor en el infractor aminora o cancela el dolor que siente por el daño recibido? Parecería que aquí interfiere algún pensamiento mágico". (2016: 51). La venganza operaría como una compensación irracional e incluso como un 'pensamiento mágico' que posiblemente tiene un fundamento en recursos adaptativos de la especie (Nussbaum 2018a: 46) 20. Pero este 'pensamiento mágico'-base de ojo por ojo- que no crea más que la ilusión de la recuperación del equilibrio que la injusticia primera nos hizo perder.

Se trata de un recurso de compensación casi tan absurdo como la "ira contra las cosas", es decir, esa ira a los objetos inanimados que de pronto no funcionan como debieran y por eso merecen nuestro "castigo porque no hacen bien su trabajo" 21 .

En realidad, lo que Nussbaum está mostrando con bastante maestría en sus ejemplos es la irracionalidad de esta ira vengativa, la carencia de un contenido cognitivo

19 "Yo voy a tratar de convencerles de que los griegos y los romanos tenían razón: la ira es un veneno para la política democrática y sus efectos son más nocivos si cabe cuando está alimentada por un miedo subyacente y una sensación de impotencia creciente. Ya estudié la ira en un libro de 2016 titulado La ira y el perdón, pero ahora tengo la sensación de que aquel análisis pasó por alto algo crucial: el papel del miedo como fuente y como cómplice de la ira vengativa. Intentaré persuadirles de que debemos resistirnos a la ira en nosotros mismos e inhibir su incidencia en nuestra cultura política" $(2019,82)$.

20 Las ideas de venganza tienen raíces profundas en la imaginación de la mayoría. En última instancia es probable que deriven de ideas metafísicas en torno al equilibrio cósmico, que son difíciles de eliminar y que pueden formar parte de nuestro legado evolutivo (p. 52).

21 Ver los comentarios de la autora frente a la 'ira contra las cosas inanimadas', a propósito de un estudio del Journal of the American Medical Association (1988) dedicado a La ira contra las máquinas expendedoras (Nussbaum 2018a, 39). 
que nos informe de algo real, a diferencia de lo que hacía la ira ante la injusticia. Esta irracionalidad, que muestra su desproporción y sobre todo su inutilidad para intervenir o cambiar el curso de las cosas. Se trata de una ira muy humana, cotidiana pero funcionalmente irracional e impotente en la restauración de un daño cometido.

La presencia de la ira vengativa y su posible consecuencia de la violencia en el espacio público-violencia explícita e implícita, circunstancial y estructural-, atenta, según Nussbaum contra la dignidad humana igualitaria, principio rector de una democracia que toma en serio su quehacer deliberativo en todos sus niveles. Como advierte la pensadora, esta dignidad no es un principio relativo, que sea parte de transacciones y compensaciones: "La dignidad no es un juego de suma cero, por esto es absolutamente diferente del estatus relativo" $(2018,56)$.

\subsection{La ira eufemística fundamento de la discriminación}

Pero no toda ira vengativa es siempre explícita y hace uso de la violencia evidente. En muchos casos, lo que aparece en el espacio público es una ira de baja intensidad, vinculada a la propagación de prejuicios, estigmas y formas de desprecio social. Encontramos aquí el alimento emocional de conductas discriminatorias naturalizadas o en vías de naturalización en una determinada comunidad política. Se trata de una ira eufemística. Tomamos el término de Giannini, que como veremos más adelante, hace un uso más específico del término.

Esta ira eufemística estaría en la base de formulación, promoción y propagación de los discursos de odio hacia grupos o comunidades. Recordemos que los discursos de odio (hate speechs) no son simplemente expresión de violencia verbal, de agravios públicos espontáneos a la honra de algunos sujetos o grupos, sino que incluyen el explícito deseo de un daño que se difunde y se socializa (Parekh 2006: 214). Esto supone estrategias discursivas públicas que implican: la específica diferenciación del grupo del resto de la comunidad, la estigmatización de sus rasgos biológicos o culturales, sociales o de clase. El proyecto a largo plazo, por cierto, de marginar a esos sujetos de la comunidad democrática, convirtiéndolos en seres considerados y tratados como “ingobernables" (Parekh 2006, 215).

La base emocional de los discursos de odio y de sus sutiles procesos de avance en la cultura pública, según Nussbaum, surge de la relación entre la ira surgida del miedo y vinculada directamente a la emoción del asco que permite proyectar ese miedo a otros (Nussbaum 2019, 110). ¿Cómo funciona esta combinación de emociones? Para Nussbaum, asumiendo la posición de algunas psicologías evolutivas, el asco primario no es una reacción sensorial simple y no cognitiva. Más bien, aprendemos a tener asco y a separarnos de aquello que comenzamos a considerar repugnante y dañino (Nussbaum $2019,111)$. En este sentido para la autora el asco es una aversión al contacto que viene motivada por un pensamiento de la contaminación (2019: 112). Nussbaum concluye que el asco está basado en un miedo mucho más profundo que simplemente el miedo a lo peligroso o dañino. Se trata del miedo "que está relacionado en cierto modo con la muerte y con la potencial descomposición del material del que estamos hechos, y eso 
es lo que hace que actúe mediante símbolos, más que a través de meras propiedades sensoriales" (2019: 114).

Según la reconstrucción de Nussbaum, este asco se proyecta y se dirige a grupos determinados, generando así una estrategia para poder convivir con este aspecto hasta cierto punto abyecto de nuestra propia humanidad. Lo explica de manera didáctica: “ ¿y si pudiéramos identificar a un grupo de seres humanos a los que viéramos como más animales que nosotros, más sudorosos, más malolientes, más sexuales, más impregnados del hedor de la mortalidad? Si identificáramos a un grupo de humanos con todo esto y los subordináramos de ese modo, tal vez nos sentiríamos más seguros" (2019: 118).

Asumiendo la perspectiva de la filósofa, hay aquí también una irracionalidad propia del asco y del miedo que proyectan odio hacia grupos concretos: Los alejamos, los marginamos, no queremos estar cerca de ellos para que no nos "contaminen", operando también aquí otra especie de pensamiento mágico: alejados de ellos estaremos a salvo de nosotros mismos.

El asco proyectivo estaría detrás de la ira eufemística que, como ira de baja intensidad, da origen a veces a sutiles discursos de odio que sustentan todas las formas de discriminación. Como le interesa mostrar a Nussbaum, este asco es moldeado socialmente, enseñado y aprendido por una cultura, por sus instituciones y costumbres (Nussbaum 2019: 30). Lo más grave es que estos discursos de odio es su gradualidad: van creando climas sociales, capaces de instalar ideas, creencias, conductas que se van convirtiendo en norma (Parekh 2006:2017). Comienzan así a penetrar prácticas sociales menores, pero en su avance pueden terminar interfiriendo en la deliberación, no solo en la esfera pública sino en la deliberación que se pretende racional de las principales instituciones democráticas, afectando la idea misma de una sociedad democrática como una sociedad que promueve la "dignidad humana igualitaria".

El comienzo del proceso de degradación de algunos grupos -como muestra magistralmente Arendt en Los orígenes de Totalitarismo- pone a la vista al comienzo, fenómenos sutiles y disimulados de ira. Expresados en la esfera pública como desprecio, burla, incluso indiferencia (Nussbaum 2019: 106 y 2014: 311), inaugurando el camino del estigma basado en características corporales o sociales (Nussbaum 2016: 14) culturales (Nussbaum, 2018a: 111 y ss). Lo que la autora norteamericana tiene a la vista sobre todo la ira en el complejo proceso de discriminación racial en EE.UU., aunque también considera las formas de ira propias de la discriminación de género.

¿Cómo se manifiesta esta ira eufemística en el lenguaje cotidiano y su uso de expresiones y discursos que tienen lugar en la esfera de opinión pública?

En el texto, titulado "El lenguaje de la ira" (1974) Giannini analiza concretamente las formas de la blasfemia y eufemia, que tienen lugar en el castellano hablado en Chile. El artículo busca analizar cómo y con qué mecanismos en el castellano de Chile ocurre el insulto a Dios. Lo interesante para nosotros son en parte las conclusiones: En el ámbito de la ira de las palabras (Santo Tomas), Giannini identifica en nuestra habla cotidiana chilena una cuestión distinta a la blasfemia. 
Lo que identifica es insulto eufemístico hacia el prójimo. Expresiones y palabras de lo más corrientes e inofensivas, son leídas por el filósofo como pequeños discursos, que resumen maldiciones de grueso calibre, pero expresadas de manera incompleta, disimulada, eufémica. Esta tendencia estaría además vinculada a la idiosincrasia chilena, que no insulta directamente, sino que crea figuras de discurso que al mismo tiempo condensan, recortan y ocultan el insulto. Desde estas reflexiones sobre la eufemia en el insulto hacia el prójimo, en el propio del lenguaje cotidiano chileno, podemos retomar el tema de discursos de odio tal como hemos venido reconstruyendo desde la posición de Nussbaum. ¿Cuáles son los nombres y los discursos que en la esfera de opinión pública asumen la forma probable del insulto eufemístico, expresando formas de discursos de odio que pueden llegar a discriminar y a excluir a grupos completos de la sociedad? Alternado sin duda las posibilidades de respeto de la "dignidad humana igualitaria" y con ello de una democracia decente.

A mi juicio, los discursos discriminatorios hacia las comunidades de la diversidad sexual son un campo de expresión de esta ira eufemística en Chile, al igual que los discursos eufemísticos que ponen en duda la igualdad de la mujeres y que abierta o veladamente terminan por limitar las posibilidades de una igualdad de género real. Quizás más grave aún por lo invisibilizados que todavía están, encontramos los discursos discriminatorios raciales y sociales, que siguen fuertemente presentes en la sociedad chilena. El prejuicio racial hacia grupos indígenas, como también la aporofobia, con todas las formas de estereotipos y prejuicios que proponen ante la opinión pública, podrían ser un amplio campo donde podemos rastrear las huellas, todavía vivas, de estos discursos de odio de baja intensidad. Estas manifestaciones de ira eufemística tienen a mi juicio directa relación con la mala calidad y la incompletitud de nuestra democracia, que no acaba aún de penetrar suficientemente los espacios sociales y cotidianos.

\section{Algunas reflexiones finales}

Si la noción de democracia debiese ser repensada y reformulada para hacerla más democrática, esto no se puede hacer hoy sin una consideración de la vida emocional, de los sujetos y las comunidades políticas.

Esto es especialmente importante en democracias incompletas, insuficientemente fuertes, en la que está ausente un ejercicio de deliberación ciudadana amplio e inclusivo que dé real sentido y orientación al quehacer democrático.

Es también especialmente importante a la hora de reprensar la deliberación como un proceso complejo, que incluye una forma de racionalidad más amplia, que aspira al menos a integrar la orientación que nos entregan las emociones en su contenido cognitivo.

Desde la perspectiva de los autores estudiados, Nussbaum y Giannini, podemos afirmar que el desarrollo y despliegue de la compasión es especialmente importante en sociedades democráticas conflictivas. En las que el desacuerdo y la diferencia ideológica, cultural, política, social puede y debe manifestarse y procesarse, sin llegar a poner en peligro la estabilidad democrática, sino ayudando a fundarla sobre bases más fuertes. En este tipo de sociedad diversa que es una sociedad democrática, la compasión permite 
"ubicarnos en el mundo", como diría Arendt, es decir, asumir una mirada más amplia y comprensiva de los otros.

Por otro lado, la ira ante la injusticia tiene en una democracia una funcionalidad moral, que permite resaltar ciertas injusticias morales poco visibles en la esfera pública. Esto es especialmente válido para sociedades "acostumbradas" a las injusticias. Esto me parece especialmente importante en democracias incompletas, en espacios públicos de deliberación restringida, cuando los mecanismos de participación e inclusión han fallado. En estos contextos, esta forma de ira puede hacer aparecer en el espacio común, injusticias inadvertidas incluso por los ciudadanos que las viven.

Esta ira ante la injusticia puede diferenciarse de la ira vengativa, que busca infligir daño de vuelta, iniciando una cadena bastante irracional que da origen al resentimiento y a la violencia, limitando las posibilidades de una esfera pública deliberativa. Parece indispensable identificar de manera más clara esa ira vengativa y sus formas de violencia evidente, pero también las formas más sutiles de ira eufemística, que preparan los ambientes a la discriminación, que se abren paso a veces por años y décadas en una cultura política cada vez más indiferente a la violencia.

En especial nos parece importante identificar las formas de ira eufemísticas, expresada en el lenguaje cotidiano, del insulto eufemístico, el trato despectivo, que crean culturas del prejuicio, la segregación y la fragmentación social, entregando las bases para discursos de odio (hate speech ), que pueden instalar formas antidemocráticas de convivencia y de discusión pública . Pero esta identificación y posterior análisis , tendrían que ser parte de un nuevo estudio específico y diferente -probablemente interdisciplinario- acerca del tema.

\section{Referencias bibliográficas}

Ahmed, S. (2014), The Cultural Politics of Emotion. Edinburgh University Press. https://www.jstor.org/stable/10.3366/j.ctt1g09x4q.15

Aquino (de), T.; H. Giannini y M. I. Flisfisch (1994), Acerca de lo malo/ Quaestiones disputatae: De malo. Santiago: Editorial Universitaria.

Arendt, H. (1994), The Origins of Totalitarianism. Hareves Book Harcourt Inc.

(1994b), Essays in Understanding, 1930-1954: Formation, Exile and Totalitarianism. Harcourt, Brace \& Co.

(1990), On Revolution. Penguin.

(1992), Lectures on Kant's Political Philosopy. University of Chicago Press.

(1996), Entre pasado y futuro. Ocho ejercicios sobre la reflexión politica. Península, 1996.

(1929), Der Liebesbegriff bei Augustin. Versuch einer philosophischen Interpretation. Julius Springer, 1929. 
Jovanovich.

(1978), The life of the Mind, ed. Por McCarthy. Harcourt Brace

Aristóteles (2007), Ética nicomáquea. Ediciones Colihue.

(2002), Retórica. UNAM.

Baños, J. (2006), Teorías de la democracia, debates actuales. Andamios 2(4): 35-58.

Barber, B. (2003), Strong democracy. Participatiory Politics for a New Age. California University Press.

Basore J. W. (1996), Seneca: Moral Essays, I. Cambridge, MA/London.

Benhabib, S. (1996), Toward a Deliberative model of Democracy Legitimacy en Benhabib, S. Democracy and Difference. Princeton University Press.

Bruna, Rosemary (2021), Emociones en diálogo: una lectura emocionista del conflicto moral en Humberto Giannini. Tesis para optar al grado de doctora en Filosofía, Facultad de Filosofía y Humanidades, Universidad de Chile, tesis dirigida por María José López Merino.

Calhoun, C. (2013), "Reliable democratic habits and emotions", Nomos 53: 212-225. https://www.jstor.org/stable/24220333

Cossarini, P. y R. García (2015), "El papel de las emociones en la teoría democrática, desafíos para un uso público de la razón en tiempos de populismo", Revista de Estudios Políticos 168: 291-315.

Dahl, R. (1971), Polyarchy: Participation and Opposition. Yale University Press.

Dahlberg, L. (2012), Radical Democracy, en B. Isakhan y S. Stockwell (eds.), The Edinburgh Companion to the History of Democracy: From Pre-history to Future Possibilities. Edinburgh University Press http://www.jstor.com/ stable/10.3366/j.cttlg0b6rb.46

Demirovic, A. (2017), "Radical democracy and socialism”, en L. Panitch y G. Albo (eds.), Rethinking Democracy: Socialist. NYU Press. https://www.jstor.org/ stable/j.ctt1pwt8df.19

Elster, J. (2012), Deliberative Democracy. Cambridge University Press. https:// www.cambridge.org/core/books/deliberativedemocracy/F8210B09ECDEDF 1479DF8D221277F119

Elster, J. (2003), "Emotions and transitional justice”, An interdisciplinary Journal 89 (1/2): 17-40. https://www.jstor.org/stable/41179084

Fraser, N. (2000), “¿De la redistribución al reconocimiento? Dilemas de la justicia en la era postsocialista", New Left Review, 2000: 126-155. [Archivo PDF] https://newleftreview.es/issues/0/articles/nancy-fraser-de-la-redistribution-alreconocimiento-dilemas-de-la-justicia-en-la-era-postsocialista.pdf

Friz, C. (22 de enero de 2015), ¿Por qué leer a Humberto Giannini? Experiencia común, diálogo y democracia. http://www.achif.cl/por-que-leer-a-humbertogiannini-experiencia-comun-dialogo-y-democracia-por-cristobal-frizecheverria/

García, R. (2015), “Representación política y democracia deliberativa. ¿Qué puede significar hoy la participación política?”, Estudios Políticos 47: 47-66. 
Giannini, H. (2015), Giannini Público. Entrevistas, Columnas, Artículos. Editorial Universitaria.

(1984), "Hacia una arqueología de la experiencia", Revista de Filosofía 23/24: 41-57.

(1975), "El lenguaje de la ira (Algunas formas locales)", Teoría 3: 46-55. https://revistas.uchile.cl/index.php/TRA/article/view/41603/43114

(1987), La reflexión cotidiana. Arqueología de la experiencia cotidiana. Editorial Universitaria.

(1987b), "Almas domiciliadas y almas callejeras (A propósito de Penélope y Odiseo)", Revista de Filosofía 29/30: 7-11.

(1965), Reflexiones sobre la convivencia humana. Publicaciones de la Facultad de Filosofía y Educación. http://libros.uchile.cl/445

(1995), Ética y negación. Estudios Públicos 58: 389-400.

(1997a), Del bien que se espera y el bien que se debe. Dolmen. http:// libros.uchile.cl/index.php/sisib/catalog/book/425

(1997b), "Hospitalidad y tolerancia (o de la tolerancia)", Revista CEP 66: 335-343.

64: 5-15.

(2008), "Experiencia moral y acción comunicativa, Revista de Filosofía

(1997c), "Discurso inaugural", Democracia y filosofía en América Latina y el Caribe, en P. Bonzi y H. Giannini (eds.), Congreso Latinoamericano sobre Democracia y Filosofía. Lom, pp. 21-26.

(1978), "Experiencia y Filosofía", Revista de Filosofía 26 (1/2): 25-32.

Gutmann, A. y D. Thompson (1996), Democracy and Disagreement. Harvard University Press.

Habermas, J. (1998), Facticidad y validez. Sobre el derecho y el Estado democrático de derecho en términos de teoría del discurso. Trotta.

Hansen, K. y C. Rostbøll (2015), "Deliberative Democracy", en B. Isakhan y S. Stockwell (eds.), The Edinburgh Companion to the History of Democracy: From Pre-history to Future Possibilities. Edinburgh University Press. https:// www.jstor.org/stable/10.3366/j.ctt1g0b6rb.47

Keane, J. (2009), The life and the death of democracy. W. W. Norton \& Company.

Kymlicka, W. (1995), Multicultural Citizenship: A Liberal Theory of Minority Rights. Clarendon Press.

López, M. (2014), “Indignación política: reflexiones desde el pensamiento de H. Arendt", Revista Alpha 38: 243-252.

(2006), "Espacio público y revolución: la modernidad republicana según Hannah Arendt”, en C. Pressaco, (ed.), Totalitarismo, banalidad y despolitización. La actualidad de Hannah Arendt. Ediciones Universidad Alberto Hurtado-Lom. 
O’Donnell, M. (2017), “The democratic deficit: institutional democracy”, en B. Jones y M. O'Donnell (eds.), Alternatives to neoliberalism: Towards equality and democracy. Bristol University Press, Policy Press. https://www.jstor.org/ stable/j.ctt1t89546.14

McLaverty, P. (2014), "Inequality and deliberative democracy", en S. Elstub y P. Mc Laverty (eds.), Deliberative Democracy: Issues and Cases. Edinburgh University Press. https://www.jstor.org/stable/10.3366/j.ctt1g0b2zh

Macpherson, C. B. (1978), La democracia liberal y su época. Alianza Editorial.

Maíz, R. (2010), “La hazaña de la razón: La exclusión fundacional de las emociones en la teoría política moderna", Revista de Estudios Políticos 149: 11-45. 132.

Mouffe, C. y E. Laclau (2004), Hegemonía y estrategia socialista. Fondo de Cultura Económica.

Mouffe, C. (1999), El retorno de lo politico. Paidós.

Nussbaum, M. (1994), The Therapy of Desire: Theory and Practice in Hellenistic Ethics (Princeton).

(2001), Upheavals of Thought. Cambridge University Press.

(2014), Emociones politicas: ¿Por qué el amor es importante para la justicia? Paidós.

(2004), Humanity: Disgust, Shame, and the Law. Princeton University Press.

(2018a), La ira y el perdón: Resentimiento, generosidad, justicia. Fondo de Cultura Económica.

(2018b), The Empire of Disgust: Prejudice, Discrimination and Policy in India and the US. Oxford University Press.

(2019), La monarquía del miedo (trad. cast.). Barcelona: Paidós.

Parekh, B. (2006), "Hate speech. Is there a case for banning?”, Public Policy Research: 2013-2023.

Peffley, M. and J. Hurwitz (2009), Racial Stereotyping and Political Attitudes: The View From Political Science en Borgida, E., Federico, C. y Sullivan, J. (eds.), The Political Psychology of Democratic Citizenship. Oxford University Press.

Renehan, R. (1963), “Aristotle's Definition of Anger”, Philologus 61-76.

Ricoeur, P. (2002), “Aristote: de la colère à la justice et à l'amitié politique”, Esprit 289 (11): 19-31.

Roemer, J. (1986), Analytical Marxism. Cambridge University Press.

Rousseau, J. (2018), Du contrat social: Principes du droit politique. Un essai de philosophie politique. Publicación Independiente.

Sokoloff, W. (2017), Confrontaional Citizenship: Reflections on Harted, Rage, Revolution, and Revolt. Sunny Press.

Smith, P. y M. Ziegler (2008), "Liberal and Illiberal Democracy in Latin America", Latin American Politics and Society 50 (1): 31-57. https://www.jstor.org/ stable/30130838 
Solomon, R. (1993), The Passions: Emotions and the Meaning of Life. Hackett Publishing Company. (2007), True of Our Feelings. Oxford University Press.

Trend, D. (1996), Radical Democracy: identities, citizenship and the State. Routledge. Van Parijs, P. (1996), Libertad real para todos: qué puede justificar al capitalismo (si hay algo que pueda hacerlo). Paidós.

Williams, M. (2000), The Uneasy Alliance of Group Representative and Deliberative Democracy, en W. Kymlicka y W. Norman (eds.), Citizenship in Diverse Societies. Oxford University Press. 124-152.

Young, M. (1996), Communication and the Other: Beyond Deliberative Democracy, en S. Benhabib, Democracy and Difference. Princeton University Press. 120136. 